\title{
O contexto escolar e a dinâmica de órgãos colegiados: uma contribuição ao debate sobre gestão de escolas
}

\author{
Angela Maria Martins*
}

\section{Resumo}

Este texto analisa dados obtidos em pesquisa realizada sobre escolas técnicas jurisdicionadas ao Centro Estadual de Educação Tecnológica Paula Souza, no Estado de São Paulo, na tentativa de compreender o campo de tensão constituído no contexto escolar, considerando as relações instauradas entre direção, professores, coordenadores pedagógicos, pais e alunos quando reunidos em órgãos colegiados e reuniões pedagógicas coletivas. Integra estudo maior no qual foram verificadas as questões que afetam a gestão da escola e o processo de construção da autonomia pedagógica, financeira e administrativa de escolas técnicas com base na análise de suas relações com os órgãos centrais (grau e nível de autonomia na organização curricular e nas questões que dizem respeito ao financiamento e à gestão da escola); os indicadores de democracia interna; as relações da direção com pais, docentes e alunos; as relações de professores com alunos; o funcionamento dos órgãos colegiados; as parcerias; a avaliação externa realizada sobre a gestão; as opiniões de professores e alunos sobre o que é um bom diretor; as opiniões da direção sobre o que é um bom aluno e um bom professor. Como dissemos anteriormente, neste texto serão discutidas apenas algumas questões que afetam a dinâmica de funcionamento dos órgãos colegiados em contexto escolar.

Palavras-chave: Órgãos colegiados. Gestão de escolas. Processos de participação.

\section{The school context and the dynamic working of the collegiate agencies: a contribution to the debate over school management Abstract}

This text analyses data obtained through research on the State Center of Technological Education Paula Souza, in the state of São Paulo, jurisdiction over technique schools; in the attempt to comprehend the tension that appears in the school context concerning the relation between directors, teachers, pedagogic coordinators, parents and students when they are congregate in collegiate agencies and in pedagogic meetings. A bigger study was integrated to this research in order to verify the issues which affect the school management and the building process of the pedagogic, financial and administrative autonomy of the technique schools based on their relations with the main agencies (degree and

"Doutora em Educação,Universidade Estadual de Campinas, SP; Professora da Universidade Católica de Santos, SP. E-mail: ange.martins@uol.com.br 
level of autonomy in the curricular organization and in the issues related to financing and school management); the internal democracy indicators; the directors relation with parents, teachers and students; the relationship between teachers and students; the workings of collegiate agencies; the partnerships, the external assessment of the management; the teachers' and students' opinion about the idea of a good director; the directors' idea of good teachers and good students. As we had already mentioned, this text will only discuss some issues that affect the working of the collegiate agencies in the school context.

Keywords: Collegiate agencies. School management. Participation process.

\section{El contexto escolar y la dinámica de órganos colegiados: una contribución al debate sobre gestión de escuelas Resumen}

Este texto analiza datos obtenidos en pesquisa realizada sobre escuelas técnicas sob jurisdicción del Centro Estadual de Educación Tecnológica Paula Souza, en São Paulo, intentando comprender el campo de tensión constituido en el contexto escolar entre dirección, subdirección, profesores, coordinadores pedagógicos, padres y alumnos cuando reunidos en órganos colegiados y reuniones pedagógicas colectivas. Integra estudio mayor en lo cual fueron verificadas las principales cuestiones que afectan la gestión de la escuela y el proceso de construcción de la autonomía pedagógica, financiera y administrativa de escuelas técnicas con base en el análisis de sus relaciones con los órganos centrales (grado y nivel de autonomía en la organización curricular y las cuestiones relacionadas al financiamiento y a la gestión de la escuela); los indicadores de democracia interna; las relaciones entre dirección, padres, docentes y alumnos; las relaciones entre profesores y alumnos; el funcionamiento de los órganos colegiados; las sociedades; la evaluación externa realizada sobre la gestión; las opiniones de profesores y alumnos sobre lo que es un buen director, las opiniones de la dirección sobre lo que es un buen alumno y un buen profesor. Son discutidas apenas algunas cuestiones que afectan la dinámica de funcionamiento de los órganos colegiados en contexto escolar. Palabras clave: Órganos colegiados. Gestión de escuelas. Procesos de participación.

\section{Introdução'}

Toda pesquisa qualitativa instaura um processo de intenso relacionamento entre pesquisadores e pesquisados, e esta questão vem sendo tratada no âmbito das discussões sobre método e metodologia de pesquisa. $\bigcirc$ controle do que comumente se chama Bias nas ciências sociais não é tarefa fácil, pois pesquisadores e estudiosos

\footnotetext{
'Esta pesquisa teve início em 2004, em escola técnica localizada na região central da cidade de São Paulo (CEETPS, 2005). Teve continuidade em 2005 incluindo uma escola técnica localizada na baixada santista, com financiamento da Fapesp. Nesta fase, integrou pesquisa maior intitulada "Educação Profissional de nível médio: construção de um novo perfil?". Originalmente este texto foi apresentado em painel intitulado "Gestão das políticas educacionais e órgãos colegiados: rumos e desafios", durante a realização do XXIII Simpósio Nacional da Associação Nacional de Política e Administração da Educação e VII Simpósio Luso-Brasileiro. O painel debateu as relações entre as diferentes esferas do poder e os níveis de funcionamento do regime democrático; os mecanismos locais de ampliação da participação dos atores escolares; os órgãos colegiados e os fluxos de financiamento.
} 
têm que fazer um esforço incomum para conter preconceitos, parcialidades e empatias no decorrer de uma investigação. Não vou entrar na seara do debate sobre pesquisas quantitativas versus pesquisas qualitativas (particularmente, sobre a possibilidade de controle de Bias nos surveys... $)^{2}$, mas não posso deixar de assinalar que, por se tratar de pesquisa qualitativa, várias interferências ocorreram ao longo do percurso inicialmente estabelecido, o que acabou configurando um caminho repleto de possibilidades abertas, tendo em vista as peculiaridades do tema analisado, a saber, o funcionamento de órgãos colegiados em escolas técnicas.

Partindo do pressuposto de que um caminho de investigação é repleto de surpresas, também assumo que o trabalho teórico não pode constituir-se apenas como "um processo para encaixar conceitos [...]. A visão prevalecente, embora normalmente implícita, é que a política é algo que é feito para as pessoas. Como beneficiários de primeira ordem, eles implementam políticas; como beneficiários de segunda ordem, eles são afetados positiva ou negativamente pelas políticas", [...], porém, "políticas colocam problemas para seus sujeitos [...] que precisam ser resolvidos no contexto" (BALL, 2006, p. 26). Apontando uma outra perspectiva nos estudos sobre políticas educacionais, o autor salienta que "sujeitos apagados emergem, resistentes e românticos, heroes althusserianos lutando contra a opressão ou contra as más práticas que os formuladores de políticas insistem em jogar em cima deles [...]". Na realidade, essas pesquisas "são caricaturas unidemensionais que falham em expor complexidades, contradições e paradoxos [....]". Prossegue afirmando que não celebra apenas a citação de dados, "que em si não garante que nos apresentemos como atores sociais autênticos e complexos ou que capturemos um senso de eventos 'inscritos....em letras de sangue e fogo' [...]. Mais apropriadamente, o ponto é a natureza da representação e da conceptualização das pessoas em nossos textos como um todo, e em nossos modelos de sociabilidade" (BALL, 2006, p. 27).

Em outra perspectiva teórica, Bourdieu, Chamboredon e Passeron (2005) assinalam que os pesquisadores presos ao banco do catecismo metodológico correm o risco de dissociar método (ou teoria) das operações de pesquisa, ou entre teoria e método ou entre teoria e teoria. Lembrando Poincaré (apud BOURDIEU; CHAMBOREDON; PASSERON, 2005) e sua premissa - os fatos não falam -, os autores sublinham que a maldição que pesa sobre sociólogos e seu jeito de fazer ciência seja o fato de lidarem com sujeitos que falam. Nesse sentido - gravar a fala, escutar, transcrever e se manter fiel às razões dadas pelos sujeitos em seus discursos -, pode fazer com que o pesquisador corra o risco de substituir suas prenoções pelas prenoções daqueles que ele escuta. Dessa forma, procurei ficar atenta às perguntas feitas, pois considerei que estas não têm o mesmo sentido para todo sujeito, tendo em vista que as diferenças de classe, culturais, econômicas e de linguagem estabelecem diferentes visões sobre o mesmo foco.

Tendo como referência esse horizonte teórico - que, embora expressem pensamentos inscritos em searas teórico-metodológicas diferentes, não são excludentes -, as entrevis-

\footnotetext{
${ }^{2}$ Goldemberg (2004, p. 46) analisa bem essa questão quando sublinha o quão difícil é essa tarefa, pois se nas pesquisas quantitativas o pesquisador pode induzir ou falsificar dados, o que diríamos de pesquisas qualitativas, nas quais os pesquisadores podem (e têm) muito mais liberdade com os entrevistados, com atitudes "que vão desde sorrisos até intervenções mais diretas".
} 
tas foram sistematizadas em categorias descritivas, com base, num primeiro momento, na fragmentação de todas elas. $\bigcirc$ material organizado foi, em seguida, analisado sob as lentes das categorias de análise. Foram analisados, ainda, documentos oficiais do Centro Estadual de Educação Tecnológica Paula Souza - CEETPS, tomando-se como referência principal os dados contidos no Sistema de Avaliação Institucional (CEETPS, 2005) - SAl, avaliação realizada por pais, professores, alunos e funcionários sobre as escolas, incluindo-se a auto-avaliação das equipes de direção. Embora sua implementação seja polêmica e discutível (os próprios professores o consideram mecanismo de controle do órgão central sobre a autonomia escolar), o SAl, ao mesmo tempo, é um dos mecanismos que possibilitam a avaliação de todos os atores envolvidos no contexto escolar, portanto, sua análise foi fundamental para realização do cruzamento de opiniões diferentes sobre os mesmos processos institucionais, tendo em vista o número de sujeitos entrevistados e o detalhamento das questões internas.

No estudo original foram verificadas as questões que afetam a gestão da escola e o processo de construção da autonomia pedagógica, financeira e administrativa de escolas técnicas com base na análise de suas relações com os órgãos centrais (grau e nível de autonomia na organização curricular e nas questões que dizem respeito ao financiamento e à gestão da escola); os indicadores de democracia interna; as ${ }^{3}$ relações da direção com pais, docentes e alunos; as relações de professores com alunos; o funcionamento dos órgãos colegiados; as parcerias; a avaliação externa realizada sobre a gestão; as opiniões de professores e alunos sobre o que é um bom diretor; as opiniões da direção sobre o que é um bom aluno e um bom professor. Como dissemos anteriormente, neste texto serão discutidas apenas algumas questões que afetam a dinâmica de funcionamento dos órgãos colegiados em contexto escolar.

Para tanto, tomou-se como referência teórica duas perspectivas de análise do contexto organizacional. Na perspectiva sociológica, considerou-se que este é constituído por níveis de lealdade institucional, diferentes graus de confiança formal e informal e de conhecimento acumulado sobre a instituição, com base na abordagem de Sennet (2006) ${ }^{4}$. Ao abordar cada um dos três movimentos, o autor sublinha que estes são tangíveis na vida de qualquer trabaIhador "e se relacionam à maneira de uma ferramenta intelectual [...] abstrata" denominada pela sociologia como capital social. Assinala as diferenças entre as duas correntes que abordam a complexidade do tema. Na visão de Putnam (apud SENNETT, 2006), o capital social pode ser visto como o envolvimento voluntário de pessoas em organizações sociais e cívicas. Na visão de Portes e White (apud SENNETT, 2006), esse envolvimento ocorre em redes, na família, na educação e no trabalho. A primeira tendência dá valor significativo à disposição que as pessoas têm para se envolver em situações voluntárias nas instituições sociais; a segunda analisa até que ponto e de que forma as pessoas se envolvem em redes de relacionamentos institucionais por vontade própria ou por necessidade, considerando a amplitude e a profundidade do envolvimento. $\bigcirc$ autor (SENNETT, 2006) vai além e analisa o julgamento

\footnotetext{
${ }^{3} \mathrm{O}$ conceito de indicadores de funcionamento de dinâmicas, movimentos ou regimes democráticos foi construído e é utilizado na área de ciência política. No entanto, na pesquisa original, ele foi utilizado livremente, o que significa que, realmente, não foram medidos os indicadores de democracia interna, apenas analisados alguns dos fatores que podem compor ou não uma gestão mais democrática da escola pública.

${ }^{4}$ Embora Sennett (2006) analise essas questões relacionadas ao mundo corporativo, considerei pertinente seu

"empréstimo" e sua livre adaptação para o estudo em pauta.
} 
que as pessoas têm de seu próprio envolvimento, o que gera altos ou baixos vínculos institucionais $^{5}$. $\bigcirc$ deficit social provocado pela dinâmica de funcionamento do capitalismo contemporâneo é o de rompimento da confiança formal e informal. A confiança formal é constituída quando uma das partes adere a um contrato acreditando que a outra parte fará honrar seus compromissos. A confiança informal "implica saber em quem podemos confiar, especialmente quando o grupo está sob pressão [...]. A confiança informal leva tempo. Numa equipe ou numa rede, as pequenas dicas de comportamento e caráter vão aparecendo aos poucos; a máscara com que nos apresentamos aos outros geralmente oculta o grau de confiabilidade que demonstraremos numa crise. Nas burocracias voltadas ao curto prazo, falta muitas vezes o tempo para desenvolver essa compreensão dos outros [...]. A reengenharia corporativa de uma instituição, trate-se de uma empresa ou de uma agência governamental, também pode reduzir drasticamente a confiança informal, pois a reorganização das relações pessoais vem abruptamente de cima e do exterior" (SENNETT, 2006, p. 65).

Na segunda perspectiva - das teorias que analisam a escola como organização burocrática - considerou-se que o conjunto legal e normativo é previsível e relativamente estável, tendo em vista que sua modificação requer processos de negociação política e/ou troca nas esferas executivas e que, ao mesmo tempo, as regras informais são configuradas e negociadas entre os pares cotidianamente diante de situações reais de trabalho, imprevisíveis (LIMA, 2003; TARDIFF; LESSARD, 2005).

No entanto, é preciso ressaltar que, como estudo de caso, algumas das características verificadas no cotidiano da dinâmica administrativo-pedagógica das escolas pode apontar tendências a serem confirmadas (ou não) em outras escolas de ensino técnico no Estado de São Paulo ou em outras redes de ensino, pois as regras normativas da política educacional são prescritivas e, como tais, constituem parâmetros para sua gestão em quaisquer níveis e esferas governamentais. No entanto, os limites decorrentes de um estudo de caso foram observados na análise dos dados.

\section{Órgãos colegiados e conflitos nos processos de participação: uma aproximação do tema}

No âmbito das organizações, os movimentos participacionistas emergiram no contexto social que estruturou o sistema de exploração e de opressão instaurado pelo capitalismo a partir do século XIX, e se consolidou a partir da primeira metade do século XX, como forma de contestação ao modelo de administração efetivado pelo taylorismo que, aliado ao fordismo, sacralizou a separação entre concepção e execução, além de introduzir tempo, espaço e movimentos rígidos na organização do trabalho. Nesse contexto de organização da produção e da vida, a participação no âmbito das organizações adquiriu várias características, dentre as quais, a participação conflitual, a participação funcional e a participação administrativa (MOTTA, 1986).

No contexto de consolidação do denominado "capitalismo da jaula de ferro", a influência da participaçãa dos atores sociais nas decisões das organizações e/ou nas decisões

\footnotetext{
${ }^{5}$ No capitalismo contemporâneo Sennett (2006) analisa os baixos graus de lealdade corporativa gerados por pressões produtivas e gerenciais.

${ }^{6}$ Expressão utilizada por muitos sociólogos na análise sobre o período de consolidação dos regimes capitalistas. Ver Sennett (2006).
} 
políticas dos regimes democráticos se limitou à construção de mecanismos de distribuição do poder, dentre os quais, as comissões e os órgãos colegiados ganharam destaque. É preciso ressaltar, porém, que os limites entre a participação efetiva de atores nesses mecanismos capazes de influenciar e alterar concretamente as decisões em favor da coletividade - e a manipulação por parte daqueles que detêm o poder utilizando-se dos mesmos mecanismos, são frágeis, tendo em vista que este é um caminho de mão dupla: ao mesmo tempo em que os atores, em situações coletivas, influenciam e podem modificar, ao menos parcialmente, as decisões que emanam de órgãos centrais, podem ser cooptados para cumprir seus objetivos.

A primeira característica que revestiu a participação no âmbito das organizações se desenvolveu como oposição ao taylorismo, baseando-se no processo de negociação coletiva entre patrões e trabalhadores, e restringindo-se, na maior parte dos casos, a negociações mediadas por diretorias de sindicatos, centrais sindicais e associações de classe. Esta dinâmica, por vezes, excluiu a participação da maior parte dos trabalhadores, mostrando-se, portanto, insuficiente como mecanismo efetivo de representação dos seus reais interesses e delimitando sua atuação direta. Outra característica diz respeito à participação de funcionários dentro das organizações (empresariais e estatais), quando se instituiu a prática de reuniões entre diferentes níveis hierárquicos visando a facilitar o fluxo de informações e os processos de negociação em torno de reorganizações administrativas. Uma terceira forma de participação nas organizações diz respeito à participação administrativa, baseada na formação de comissões de funcionários eleitos como representantes por tempo determinado. Este é o modelo dos órgãos colegiados sujeitos a ajustes em função de mudanças conjunturais de legislação e de normas (podem ser consultivos, deliberativos, etc.), mas que permanecem como princípio de participação por representação de funcionários no âmbito das organizações.

Qualquer um dos mecanismos de participação, no entanto, traz em seu bojo o campo de conflitos instaurado em função dos diferentes interesses que se entrecruzam no contexto das organizações. $\bigcirc$ contexto organizacional, nesse sentido, adquire características peculiares em função da capacidade que a própria organização demonstra ao administrar esse campo de tensão. É preciso ressaltar, também, que são poucos os estudos sobre conflitos gerados em processos de negociação que ocorrem em reuniões de órgãos colegiados. A discussão sobre conflitos no contexto escolar está quase sempre associada à questão da violência entre os alunos, entre estes e os professores, entre a direção e os alunos etc. De qualquer forma, é importante assinalar que para este estudo, considerou-se a noção que define os processos de participação como sendo aqueles constituídos por uma dinâmica individual e coletiva, que opera concomitantemente. Na visão de diferentes sociólogos, ao praticar a ação, todo ator mantém sempre uma margem relativa de autonomia, conferindo à sua participação significados que variam de acordo com os contextos sociais, políticos, econômicos da sociedade e da organização onde ele se insere7 (MEISTER, 1981 ; CROZIER, 1963; GIDDENS, 1995; TOURAINE, 2001). Várias críticas, no entanto, têm sido feitas a essa visão, tendo em vista que se corre o risco de substituir pela primazia da esfera política e da ação do Estado a primazia da ação do ator individual.

\footnotetext{
${ }_{7}^{7}$ Albert Meister (1981) é um dos sociólogos cuja obra é referência para o debate em torno das questões de participação. Estudou algumas das experiências associativas contemporâneas, particularmente, os kibutz israelenses, a autogestão iuguslava, o sistema institucional mexicano, os mecanismos de promoção social através da educação de adultos na França e a experiência das cooperativas criadas durante o governo do General Juan Velasco Alvarado, no Peru, em 1968.
} 
De qualquer forma, os regimes democráticos têm viabilizado e canalizado a participação dos atores - seja no âmbito político ou no âmbito das organizações -, através da instituição de canais legitimados para tanto: eleições livres baseadas em princípios de representação política; conselhos que funcionam em vários níveis e esferas de governo; conseIhos administrativos; conselhos de representação de funcionários, deliberativos ou consultivos, etc. De um lado, no que tange ao aspecto formal, estes mecanismos estão submetidos ao conjunto legal e normativo que impõe regras e determina níveis e modalidades de funcionamento, estabelecendo o que alguns sociólogos denominam participação organizada e imposta (MEISTER, 1981) e a escola tem sido apontada como uma das organizações sociais mais afetadas nesse processo. De outro lado, vários estudos - embora inseridos em searas teórico-metodológicas diferentes entre si - se dedicam a analisar os mecanismos da participação em seu contexto, assinalando a complexidade que reveste a tradução feita pelos atores escolares sobre a configuração do conjunto legal e normativo, originando processos organizacionais imprevisíveis (BALL, 2006; TARDIFF; LESSARD, 2005; LIMA, 2003).

Nesse sentido, no que diz respeito aos aspectos informais que configuram em boa medida o cotidiano das organizações, os atores respondem de maneiras diferentes às orientações normativas, constituindo um campo de tensão, pois há um processo de re significação, de releitura ou de reinterpretação do conjunto legal por parte de professores, diretores e coordenadores de escolas públicas, bem como há diferentes formas de apreensão destes sobre o exercício da docência e da gestão, considerando-se os contextos nos quais são formados e exercem sua profissão.

○ campo de tensão constituído nesse processo pode potencializar comportamentos de resistências, omissões, dissimulações e/ou simplesmente de adesões às orientações oficiais por meio de cumprimento formal das diretrizes emanadas. Acrescente-se que a cultura institucional - o sistema de crenças, valores e de interação dos atores entre si e entre estes e a própria organização -, ao ser instado a se modificar, metaforiza parte do ritual normativo. Da mesma forma, o clima organizacional - as técnicas e procedimentos; a política de recursos humanos; as metas, regulamentos e estatutos; o comportamento encorajado dentro da instituição, bem como as atividades integradoras, também sofrem um processo de aprendizagem em situações de conflitos.

\section{A dinâmica de órgãos colegiados em escolas técnicas: a análise de um paradoxo}

As escolas analisadas apresentam peculiaridades em função da capacidade de liderança e de mediação das equipes de direção ${ }^{8}$, da articulação realizada em reuniões da Associação de Pais e Mestres - APM, e do fluxo de informações em reuniões pedagógicas coletivas e de órgãos colegiados. $\bigcirc$ papel das equipes de direção, em ambos os casos analisados, é central nos processos de negociação em torno das questões curriculares, financeiras e administrativas. Tendo em vista serem escolas técnicas, as unidades contam com poucos alunos menores de idade, cujos pais não se vêem incentivados para participar de reuniões, sejam da APM ou de qualquer outro órgão colegiado (os pais de alunos maiores de idade não podem ser convocados para reuniões escolares).

\footnotetext{
${ }^{8}$ As equipes de direção, nessas escolas, são constituídas pelo diretor, vice-diretor, coordenadores pedagógicos e coordenadores de área.
} 
No que diz respeito ao funcionamento de um dos principais órgãos colegiados de escolas, a APM, esta associação vem assumindo um papel de captador de recursos no caso das escolas técnicas no Estado de São Paulo. Cada vez mais as unidades dependem da taxa de inscrição para o "vestibulinho" de ingresso a cada semestre. Durante a segunda gestão do governador Alckmin (2002/2005), as escolas técnicas subordinadas ao CEETPS foram apontadas na agenda de governo como uma de suas prioridades, conhecidas por formar alunos que encontram emprego com facilidade ou que passam em vestibulares concorridos, porém, parte dessa qualidade tem sido mantida com o dinheiro dos próprios estudantes. A verba chega às escolas por meio de doações de alunos e de pais às APMs, em valores que variam de $\operatorname{R} \$ 50,00$ a R\$200,00 por semestre. São essas associações que compram boa parte dos materiais de limpeza e de escritório, além de renovarem os equipamentos dos laboratórios.

Em artigo anterior (MARTINS, 2005), assinalei que grande parte das contas das escolas tem sido paga diretamente pelo Centro Paula Souza (água, luz e a folha de pagamento de professores e da maioria dos funcionários), no entanto, as verbas são irrisórias para manutenção, principalmente, da qualidade dos laboratórios, essenciais na formação profissional. Segundo Takahashi (2005), dados do Sigeo (sistema disponível aos deputados estaduais para acompanhar o quanto o governo gasta do Orçamento) apontam que a gestão Alckmin empenhou (liberou), até outubro de 2005, apenas 29,3\% da verba prevista para equipamentos e material permanente em 2005 e 0,2\% para obras e instalações. De acordo com o SAI (CEETPS, 2005), a média de custo/aluno de todas as ETE's foi de R\$2.030,31 e a média do custo/aluno das ETE's com todas as despesas incluídas foi de $\mathrm{R} \$ 2.296,23^{9}$.

Nesse sentido, a APM, diferentemente do que ocorre na maior parte das escolas, não precisa trabalhar durante o ano para fazer festas e realizar outras arrecadações. Talvez, este seja um dos motivos que possam justificar o fato de os pais não se sentirem atraídos para participarem desse órgão colegiado. No entanto, isso gera, também, uma contradição. De um lado, na avaliação realizada pelos pais sobre as escolas (CEETPS, 2005), há críticas exatamente sobre o fato de as APMs não realizarem festas e outras reuniões ao longo do semestre letivo, e muitos pais vêem essa questão como ausência de motivação para participar da vida escolar. De outro lado, no mesmo documento de avaliação, professores e funcionários elogiam o funcionamento da APM e dizem que esta é uma associação bastante ativa em função do aporte financeiro que propicia à escola, facilitando a implementação de alguns projetos curriculares, a compra de equipamentos para laboratórios, etc.

Foi possível verificar que há uma relação de confiança entre professores, funcionários, direção e alunos, porém, durante o convívio observei, também, conflitos que ao invés de corroer o grau de confiabilidade e legitimidade de autoridade, pelo contrário, parecem suscitar um processo coletivo de busca de soluções para os problemas provocados por fatores endógenos e exógenos. Ao que tudo indica, o clima organizacional é constituído

\footnotetext{
${ }^{9} \mathrm{O}$ custo/aluno é calculado pelo somatório de todos os salários, encargos sociais, despesas de custeio, serviços, custos da administração central e subsídios da FAT, dividido pelo total de alunos matriculados na ETE. Desse cálculo são excluídos inativos e complemento salarial. O Centro também esclarece que os recursos são os mesmos para todas as ETE's, portanto, este cálculo é importante sinalizador de gestão, "pela possibilidade de ver a relação custo-benefício de todas as ações desenvolvidas" (CEETPS, 2005).
} 
por diferentes níveis de lealdade institucional, alto grau de confiança informal e de conhecimento acumulado sobre a instituição, o que configura um capital social nada desprezível, tendo em vista o julgamento que as pessoas têm do seu próprio envolvimento com as dinâmicas de funcionamento das escolas, considerado como elevado por todos os entrevistados. Nesse sentido, as unidades analisadas não estão submetidas a deficit de lealdade, confiança e conhecimento dos mecanismos institucionais, fenômeno que vêm afetando as estruturas e o funcionamento das instituições contemporâneas.

O CEETPS é uma instituição com características de secretaria de educação, considerando-se sua estrutura e funcionamento. É uma organização fortemente centralizada, ainda calcada nos moldes burocráticos de sua origem, isto é, centrada em elementos prescritivos e normativos, processos de planejamento e tomadas de decisão de médio e longo prazos, visando a cumprir objetivos e metas que promovam elevados níveis de consenso institucional, o que acaba por constituir um paradoxo. Embora as políticas educacionais venham promovendo reformas sistemáticas nos sistemas de ensino e inovações nas escolas, muitas das características configuradas no denominado período da "burocracia da jaula de ferro" ainda sobrevivem na dinâmica de funcionamento de instituições governamentais, como é o caso em pauta.

Não se trata, neste texto, de discutir a polissemia da palavra burocracia, muito menos de entrar na seara dos teóricos que disputam o entendimento do legado weberiano, no que tange à constituição de modelos teóricos das organizações ${ }^{10}$, porém, é interessante assinalar que, embora o CEETPS se paute por um modelo que pode ser denominado burocrático-racional, e, conseqüentemente, as unidades a ele ligadas devam pautar-se pelas características desse modelo, há a constituição, no cotidiano dessas escolas, de alto grau de imprevisibilidade que atravessa o conjunto das regras jurídicas e normativas. Pode-se afirmar com certa tranqüilidade, após o longo período de convivência nas unidades, que sua dinâmica geral pode ser examinada à luz dessa aparente ambigüidade.

As relações estabelecidas no cotidiano e em situações de reuniões colegiadas são tecidas em processos de longas negociações e conflitos, tanto no que diz respeito às diretrizes centrais (acentuadas diante das características fortemente burocrático-racionais da instituição), quanto no que diz respeito à busca de soluções para problemas do cotidiano, que não são poucos, tendo em vista a insuficiência de verbas para a área. No entanto, as equipes de direção conseguem achar brechas nos buracos provocados pela desconexão das orientações normativas e encontrar caminhos próprios cunhados entre regras formais e informais. Tendo em vista as demandas que recaem sobre as escolas (no que diz respeito às orientações centrais e no que tange à procura dos cursos pelas comunidades), essas equipes têm encontrado saídas através da instauração de regras informais que possam suscitar a construção de caminhos alternativos para suprir a insuficiência de verbas, por exemplo. Porém, esses caminhos alterna-

\footnotetext{
${ }^{10}$ Concordo com Lima (2003, p. 41), quando este autor assinala que os estudos sociológicos da escola como organização são poucos. Da mesma forma, também há pouca produção de conhecimento sobre a organização não exclusivamente formal das instituições de ensino e uma predominância da visão centralista-burocrática "transformada em convicção e em teoria explicativa sem exame teórico e empírico", o que tem provocado "uma fixação no plano das orientações e a redução deste à dimensão jurídica e formal". Nesse sentido, o autor critica os modelos teóricos baseados na concepção burocrático-racional para analisar instituições educativas e aponta a necessidade de que essa perspectiva jurídica, normativa e legal (muitas vezes produzida pela própria administração central), seja confrontada com as práticas dos atores "com as estratégias levadas a cabo por grupos e subgrupos nas organizações".
} 
tivos cada vez mais se configuram como busca de parcerias com empresas e autarquias das regiões onde estão alocadas, para manutenção da infra-estrutura escolar.

Verificou-se que não há diferenças no fluxo interno de informações (com ausência absoluta de filtro de informações por subgrupos de interesses), tanto no cotidiano quanto nas reuniões dos órgãos colegiados, sendo que este ocorre com base em processo flexível e na defesa de projetos comuns que são compartilhados por professores de diferentes áreas, coordenadores pedagógicos e direção. Entretanto, no que diz respeito às informações advindas dos órgãos centrais, estas são filtradas internamente revelando interesses e conflitos de subgrupos, isto é, entre equipes de direção, corpo docente e administrativo, quando o papel e a função de cada ator escolar se define diante do aparato burocrático da administração central.

Embora diretores, professores e funcionários administrativos possam sentir-se inseguros em situações de conflitos gerados em reuniões de órgãos colegiados nos processos institucionais, o campo de tensão constituído, pode, às vezes, funcionar como o estímulo que faltava para implementação de idéias comuns que geram projetos coletivos. Algumas escolas se aproveitam de períodos de reformas nos sistemas de ensino ou de inovações exigidas e implementadas por órgãos centrais para produzirem idéias e projetos próprios, apesar dos conflitos constituídos nos processos de negociação em torno de sub-grupos de interesses que inevitavelmente se formam nessas situações coletivas, quando emergem disputas por controle das situações institucionais.

De acordo com Ball (1989), o controle é a tentativa de resolver ou evitar conflitos e pode ser exercido na escola tanto pela direção, quanto por grupos ou pessoas de maior influência. Nas escolas analisadas, as equipes de direção apresentaram capacidade de administração de conflitos nas reuniões dos órgãos colegiados, o que gera certo controle sobre as relações institucionais, porém não diminui o nível de instauração de dinâmicas escolares mais democráticas. Pelo contrário. As unidades contêm dois movimentos: um, de conflitos instaurados em função das negociações que se estabelecem frente às diretrizes normativas advindas dos órgãos centrais, cuja dinâmica é até incentivada pelas equipes de direção como forma de motivação para que professores e funcionários tenham conhecimento das demandas que recaem sobre as escolas e se posicionem diante do aparato legal e normativo, retirando, de certa forma e até certo ponto, a responsabilidade solitária das equipes de direção para tomar decisões cruciais em conjuntura adversa; outro, de aparente acomodação dos professores após a conquista de interesses pontuais.

Assim, determinados conflitos surgem nesse campo de interesses opostos, constituídos por sujeitos que ocupam posições diversas no mesmo espaço físico e simbólico. Muitos diretores e docentes, com certeza, se vêem frente a situações de conflitos semelhantes e as enfrentam de formas totalmente diferentes, pois como assinalam Tardiff e Lessard (2005) não há receituário ou livro didático orientando sobre o que fazer nos espaços coletivos de confrontos, tendo em vista que as atividades que envolvem a docência, as equipes de direção, os alunos e a comunidade de pais são impregnadas de experiência individual e social, constituindo um campo de tensão frente às políticas definidas para a rede de escolas por órgãos centrais baseados na tradição burocrático-racional. Essa tensão pode ser apontada como o elemento que instaura a imprevisibilidade nas relações cotidianas e, sobretudo, nos (des) caminhos das orientações normatizadoras quando postas à prova em reuniões de órgãos colegiados. 


\section{Referências}

BALL, S. La micropolítica de la escuela. Madrid: Paidós: MEC, 1989.

Sociologia das políticas educacionais e pesquisa crítico-social: uma revisão pessoal das políticas educacionais e da pesquisa em política educacional. Currículo Sem Fronteira, Rio de Janeiro, v. 6, n. 2, p. 10-32, jul./dez. 2006.

BOURDIEU, P.; CHAMBOREDON, J.C.; PASSERON, J. C. Ofício de sociólogo. Petrópolis: Vozes, 2005.

CEETPS. Sistema de avaliação institucional. São Paulo, 2005.

CROZIER, M. Le phénomene bureaucratique. Paris: Editions du Seuil, 1963.

GIDDENS, A. Modernity and self-identity. Cambridge: Polity Press, 1995.

GOlDEMBERG, M. A arte de pesquisar. Rio de Janeiro: Record, 2004.

LIMA, L. C. A escola como organização educativa. São Paulo: Cortez, 2003.

MARTINS, A. M. A gestão de uma escola técnica: desafios pedagógicos. In: PONTIFÍCIA UNIVERSIDADE CATÓLICA DE SÃO PAULO (Org.). Programa de Estudos Pós-Graduados em Educação: psicologia da educação, Campinas: Autores Associados, 2005.

MEISTER, A. L'autogestion en uniforme. Toulouse: Privat, 1981.

MOTTA, F. C. P. Teoria das organizações: evolução e crítica. São Paulo: Pioneira, 1986.

SENNET. R. A cultura do novo capitalismo. Rio de Janeiro: Record, 2006.

TAKAHASHI, F. Pais socorrem escolas técnicas de Alckmin. Folha de São Paulo, São Paulo, 3 nov. 2005.

TARDIFF, M.; LESSARD, C. O trabalho docente: elementos para uma teoria da docência como profissão de interações humanas. Petrópolis: Vozes, 2005.

TOURAINE, A. Que es la democracia? México: Fondo de Cultura. 2001.

Recebido em: 24/04/2008

Aceito para publicação em: 28/04/2008 